\title{
Total strong litact domination in graphs
}

\author{
A.Renuka Lakshmi ${ }^{1 *}$, M.Vani ${ }^{2}$, Ch.Ramprasad ${ }^{3 *}$, J.Vijaya Kumar ${ }^{4}$ \\ Vasireddy Venkatadri Institute of Technology, Nambur, 522 508, Andhra Pradesh, India ${ }^{1-4}$.
}

\begin{abstract}
In this paper, a new domination number called total strong litact domination number is defined on a graph and values of the defined variant to standard graphs, general graphs, trees etc., are acquired and endeavoured to raise a association among the total strong litact domination number of a litact graph of $\mathrm{G}$ with distinct parameters of $\mathrm{G}$ and also with additional domination parameters of G.
\end{abstract}

Subject classification number: AMS-05C69, 05C70.

Keywords: graph, Litact graph, Litact domination number, total strong litact domination number.

\section{INTRODUCTION}

Simple, finite, non-trivial, undirected and connected graphs are used to represent the symbols. Every symbol and corresponding definitions can be found in F.Harary [2] and V.R.Kulli [9].

The conceptualization of strong domination number was initiated by Sampath kumar and Pushpa Latha in [6]. The conceptualization of total domination number of a graph was initiated by Cocakayne, Dawes and Hedetniemi in [1]. We are focused in perceiving the total strong domination for a litact graph which was initiated and explained by M.H.Muddebihal [4].

\section{Definition 1.1: Litact Graph:}

A graph $G$ is said to be a litact graph $m(G)$ is a graph whose vertex set is the union of the edge set and cut vertex set of $G$ where two vertices are adjacent if and only if the corresponding edges and the cut vertices are adjacent or incident on $\mathrm{G}$.

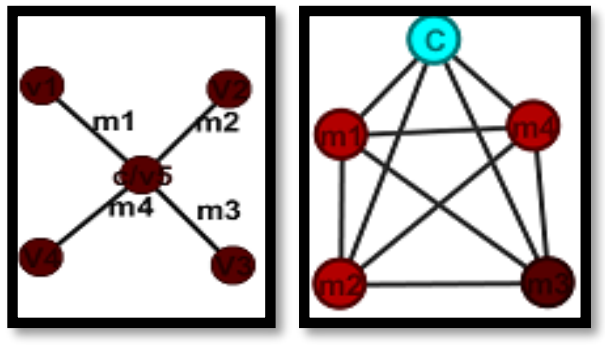

Fig:1 Graph and Litact Graph $\mathbf{m}(\mathbf{G})$

Definition 1.2: Litact domination number:

A dominating set $\mathrm{D} \subseteq \mathrm{V}(\mathrm{m}(\mathrm{G}))$ is called litact dominating set of $\mathrm{G}$, if every vertex in $\mathrm{V}(\mathrm{m}(\mathrm{G}))-\mathrm{D}$ is adjacent to a vertex $v$ in $D$. Litact domination number of $G$, is denoted by $\gamma_{m}(G)$ and is defined as $\gamma_{m}(G)=\min |D|$.

Example 1: In the figure $1, \gamma_{m}(G)=1$

\section{Definition 1.3: Strong litact domination number:}

A set $D \subseteq V(m(G))$ is a strong litact dominating set of $m(G)$, if for every vertex $x \in V(m(G))$ - Dthere is a vertex y $\in$ D with $x y \in E(G)$ and $\operatorname{deg}(x, m(G)) \leq \operatorname{deg}(y, m(G))$. The strong litact domination number $\gamma_{\text {stm }}(G)$ is defined as the minimum cardinality of a strong litact dominating set.

Example 2: In the fig $1, \gamma_{\text {stm }}(G)=1$

\section{Definition 1.4: Total Strong litact domination number:}

A strong litact dominating set $\mathrm{D} \subseteq \mathrm{V}(\mathrm{m}(\mathrm{G}))$ is said to be total if the subgraph induced by $\mathrm{D}$ has no isolated vertices. Total strong litact domination number in $m(G)$ is denoted by $\gamma_{\mathrm{tsm}}(G)$ and is defined

as $\gamma_{\mathrm{tsm}}(\mathrm{G})=\min |\mathrm{D}|$

Example 3: In the fig $1, \gamma_{\mathrm{tsm}}(\mathrm{G})=2$ 


\section{International Advanced Research Journal in Science, Engineering and Technology \\ Impact Factor $7.105 \div$ Vol. 9, Issue 1, January 2022 \\ DOI: 10.17148/IARJSET.2022.9140}

\section{RESULTS AND OBSERVATIONS:}

\subsection{To get more distant results, we need the following theorems}

Theorem A [8]: If $G$ is a graph of order $p$ without isolated vertices then $\gamma(G) \leq \frac{p}{2}$

Theorem B[8]: For any graph $\mathrm{G}, \operatorname{diam}(G)-1 \leq \gamma_{C}(G)$.

Theorem C[8]: For any graph $\mathrm{G},\left\lceil\frac{p}{\Delta(G)+1}\right\rceil \leq \gamma(G)$

Theorem D[11]: For any graph G, $\gamma(G) \leq \gamma_{C}(G)$

Theorem E [8]: For each graph $G, \alpha_{0}(G)+\beta_{0}(G)=p$ and if $G$ has no $\beta_{1}(G)=p$.

Theorem F [11]: For each graph $G, \gamma(G) \leq p-\Delta(G)$.

Theorem G [11]: For each graph $G, \gamma(G) \leq \beta_{0}(G)$.

Theorem $H$ [8]: If $G$ has p vertices and no isolates then $\gamma_{t}(G) \leq p-\Delta(G)+1$.

Theorem I [8]: If $G$ is a connected graph, then $\left\lceil\frac{\operatorname{diam}(G)+1}{3}\right\rceil \leq \gamma(G)$.

Theorem J [8]: For any connected graph, $\gamma_{\mathrm{c}}(\mathrm{G}) \leq \mathrm{p}-\Delta(\mathrm{G})$.

Theorem K [8]: For any graph $\mathrm{G} p-\mathrm{q} \leq \gamma(\mathrm{G})$. Further more $\gamma(\mathrm{G})=\mathrm{p}-\mathrm{q}$ if and only if each component of $\mathrm{G}$ is a star.

\subsection{OBSERVATION}

Litact graph of star graph is Regular.

\section{THEOREMS}

Theorem 3.1:

$\mathrm{p}_{2}, \gamma_{\mathrm{tsm}}\left(\mathrm{K}_{\mathrm{p}_{1}, \mathrm{p}_{2}}\right)=2$
a) For any cycle graph $C_{p}, p>3$ vertices, $\gamma_{t s m}\left(C_{p}\right)=\left\lceil\frac{p}{3}\right\rceil$
b) Every Path graph $\mathrm{P}_{\mathrm{p}}, \mathrm{p}>3$ vertices, $\gamma_{\mathrm{tsm}}\left(\mathrm{P}_{\mathrm{p}}\right)=\left\lfloor\frac{\mathrm{p}}{2}\right\rfloor$
c) Every Wheel graph $W_{p}, p \geq 4$ vertices, $\gamma_{\text {tsm }}\left(W_{p}\right)=\left\lfloor\frac{p+2}{3}\right\rfloor$
d) Every complete graph $K_{p}, p>3$ vertices, $\gamma_{t s m}\left(K_{p}\right)=2$
e) Every star graph $K_{1, p}, p>3$ vertices, $\gamma_{\text {tsm }}\left(K_{1, p}\right)=2$
f) Every Complete bipartite graph $\mathrm{K}_{\mathrm{p}_{1}, \mathrm{P}_{2}}, \mathrm{P}_{1}, \mathrm{P}_{2} \geq 2$ vertices and $\quad \mathrm{p}=\mathrm{p}_{1}+$ of $G$.

Theorem 3.2: Every graph $G, \gamma_{\text {tsm }}(G)<p$.

Proof: Let $V(G)$ be the set of vertices in $G$.Let $V(m(G))=E(G) \cup C(G)$ where $E(G)$ is the set of edges and $C(G)$ is the set of cut vertices of G.Let $D_{1} \subseteq V(m(G))$ be minimal strong dominating set of $m(G)$, i.e $\operatorname{deg}\left(v_{i}\right) \leq \operatorname{deg}\left(v_{j}\right), v_{i} \in$ $\mathrm{V}(\mathrm{m}(\mathrm{G}))-\mathrm{D}_{1} \&$ it has no isolated vertices then $\mathrm{D}_{1}$ itself forms a $\gamma_{\text {tsm }}-$ set. Otherwise there exists $v_{i} \in D_{2} \subseteq$ $V(m(G))$ such that $\left|D_{1} \cup D_{2}\right|$ forms a minimal total strong litact dominating in $G$. That is $\left|D_{1} \cup D_{2}\right|=\gamma_{\text {tsm }}(G)$ then we have $V(m(G)) \leq 2 p$

$$
\begin{gathered}
\text { Also }\left|D_{1} \cup D_{2}\right|<\left[|V(m(G))|-\left|D_{1} \cup D_{2}\right|\right. \\
\left|D_{1} \cup D_{2}\right|+\left|D_{1} \cup D_{2}\right|<|V(m(G))| \\
2\left|D_{1} \cup D_{2}\right|<|V(m(G))| \leq 2 p \\
2 \gamma_{\text {tsm }}(G)<2 p \\
\gamma_{\text {tsm }}(G)<p \\
\gamma_{\text {tsm }}(G)<p
\end{gathered}
$$

The following corollary relates total strong litact domination number of $\mathrm{G}, \mathrm{v}(\mathrm{G})$ and $\Delta(\mathrm{G})$

Corollary 3.1: For any graph $G,\left[\frac{p}{1+\Delta(G)}\right] \leq \frac{3 p}{2}-\gamma_{\text {tsm }}(G)$

Proof: Proof follows from Theorem A, Theorem C and Theorem 3.2. 


\section{International Advanced Research Journal in Science, Engineering and Technology \\ Impact Factor $7.105 \div$ Vol. 9, Issue 1, January 2022 \\ DOI: $10.17148 /$ IARJSET.2022.9140}

The ensuing corollary gives the interrelation among total strong litact domination number, degree of $\mathrm{G}$ and domination number of $\mathrm{G}$

Corollary 3.2: For any graph $\mathbf{G}, \boldsymbol{\gamma}_{\mathrm{tsm}}(\mathbf{G})<\Delta(\mathbf{G})+\boldsymbol{\gamma}(\mathbf{G})$

Proof: From theorem 3.2 we have $\gamma_{\mathrm{tsm}}(\mathrm{G})<\mathrm{p}$

Theorem F we have $\gamma(\mathrm{G}) \leq \mathrm{p}-\Delta(\mathrm{G}) \ldots \ldots(2)$

Subtract (2) from (1) we get $\gamma_{\mathrm{tsm}}(\mathrm{G})<\Delta(\mathrm{G})+\gamma(\mathrm{G})$.

The ensuing Theorem gives the interrelation among total strong litact domination number, $\alpha_{0}(G) \& \beta_{0}(G)$

Theorem 3.3: Every graph $G, \gamma_{\text {tsm }}(G)<\alpha_{0}(G)+\beta_{0}(G)+\gamma(G)$.

Proof: Let $A \subseteq V(G)$ be the stow of vertices with $\operatorname{deg}\left(v_{i}\right) \geq 2 \forall v_{j} \in A, 1 \leq i \leq m$ which covers all the edges in $G$. Clearly $|\mathrm{A}|=\alpha_{0}(G)$. Additionally if some vertex $\mathrm{x} \in \mathrm{A}, \mathrm{N}(\mathrm{x}) \in \mathrm{V}(\mathrm{G})-\mathrm{A}$. Then A itself forms maverick vertex set. Or else $A_{1} \cup A_{2}$ where $A_{1} \subseteq A$ and $A_{2} \subseteq V(G)-A$ is an maximum maverick set of $G$ with $\left|A_{1} \cup A_{2}\right|=\beta_{0}(G)$. Let $B=$ $\mathrm{A}^{\prime} \cup \mathrm{A}^{\prime \prime}$ where $\mathrm{A}^{\prime} \subseteq \mathrm{A}$ and $\mathrm{A}^{\prime \prime} \subseteq \mathrm{V}(\mathrm{G})-\mathrm{A}$ be the minimal stow of vertices which covers all the vertices in G. Clearly $\mathrm{B}$ forms a minimal $\gamma$ - set of $G$. Let $\mathrm{D} \subseteq \mathrm{V}(\mathrm{m}(\mathrm{G}))$ be a minimal strong litact dominating set in $\mathrm{m}(\mathrm{G})$ and assume $\mathrm{D}_{1} \subseteq$ $\mathrm{V}(\mathrm{m}(\mathrm{G}))-\mathrm{D}$. Then take $\mathrm{D}_{1}^{\prime} \subseteq \mathrm{D}_{1}$ such that $\left(\mathrm{D}_{1}^{\prime} \cup \mathrm{D}_{1}\right)$ has no isolated vertices. Evidently $\mathrm{D}_{1}^{\prime} \subseteq \mathrm{D}_{1}$ is an total strong dominating set in $m(G)$. It follows that $|D| \subseteq|A| \cup\left|A_{1} \cup A_{2}\right| \cup|B|$. Hence $\gamma_{\text {tsm }}(G)<\alpha_{0}(G)+\beta_{0}(G)+\gamma(G)$.

The following corollary interrelates total strong litact domination number of $\mathrm{G}, \mathrm{p} \& \gamma(\mathrm{G})$

Corollary 3.3: For any connected $(\mathbf{p}, \mathbf{q}) \operatorname{graph} \mathbf{G}, \boldsymbol{\gamma}_{\mathrm{tsm}}(\mathbf{G})<\mathrm{p}+\gamma(\mathbf{G})$.

Proof: Proof follows from Theorem E and Theorem 3.3.

The following corollary relates total strong litact domination number, p, $\Delta(G) \& \gamma(G)$

Corollary 3.4: For any graph $\mathbf{G}, \mathbf{2} \boldsymbol{\gamma}_{\mathrm{tsm}}(\mathbf{G})<\mathrm{p}+\Delta(\mathbf{G})+\mathbf{2} \boldsymbol{\gamma}(\mathbf{G})$

Proof: Proof follows by adding Corollary 3.2 and Corollary 3.3 .

The following corollary relates total strong litact domination of $G, p$ and $\gamma(G)$

Corollary 3.5: In a graph $G, \gamma_{\mathrm{tsm}}(G) \leq p+\left\lceil\frac{\gamma(G)}{2}\right\rceil$

Proof: Addition of theorem $F$ and corollary 3.4 we get the result $\gamma_{\text {tsm }}(G) \leq p+\left\lceil\frac{\gamma(G)}{2}\right\rceil$

The ensuing theorem interrelates $\gamma_{\mathrm{c}}(\mathrm{G}) \& \gamma_{\mathrm{tsm}}(\mathrm{G})$.

Theorem 3.4: Every graph $\mathbf{G}, \boldsymbol{\gamma}_{\mathbf{c}}(\mathbf{G})<3 \boldsymbol{\gamma}_{\mathrm{tsm}}(\mathbf{G})$.

Proof: Let $D$ be a connected dominating set of $\mathrm{G}$ such that $|D|=\gamma_{C}(G)$.Let $\mathrm{D}_{1}$ be the minimal strong dominating set of $\mathrm{m}(\mathrm{G})$. Assume $D_{2} \subseteq V(m(G))-D_{1}$. Then take $D_{2}^{\prime} \subset D_{2}$ such that $\left\langle D_{2}^{\prime} \cup D_{1}\right\rangle$ has no isolated vertices in $\mathrm{m}(\mathrm{G})$ and it gives $D_{2}^{\prime} \subset D_{1}$ minimal total strong dominating set in $\mathrm{m}(\mathrm{G})$. Clearly $\frac{|\mathrm{D}|}{3} \subset\left|\mathrm{D}_{2}^{\prime} \cup \mathrm{D}_{1}\right|$. Hence $\frac{\gamma_{\mathrm{c}}(\mathrm{G})}{3}<$ $\gamma_{\mathrm{tsm}}(\mathrm{G})$.

Therefore, $\gamma_{\mathrm{c}}(\mathrm{G})<3 \gamma_{\mathrm{tsm}}(\mathrm{G})$.

The following corollary relates total strong litact domination and domination number of $\mathrm{G}$.

Corollary 3.6: For any graph $G, \gamma(G)<3 \gamma_{\text {tsm }}(G)$.

Proof: Proof follows from theorem 3.4 and theorem D.

The ensuing theorem relates total strong litact domination number of $\mathrm{G}$ and diameter of $\mathrm{G}$.

Theorem 3.5: Every graph $G,\left\lfloor\frac{\operatorname{diam}(G)-1}{3}\right\rfloor<\gamma_{\mathrm{tsm}}(G)$.

Proof: From Theorem B and Theorem 3.4 we getdiam $(G)-1<3 \gamma_{\text {tsm }}(G)$ this gives $\left\lfloor\frac{\operatorname{diam}(\mathrm{G})-1}{3}\right\rfloor<\frac{\operatorname{diam}(\mathrm{G})-1}{3}<\gamma_{\mathrm{tsm}}(\mathrm{G})$ and $\left\lfloor\frac{\operatorname{diam}(\mathrm{G})-1}{3}\right\rfloor<\gamma_{\mathrm{tsm}}(\mathrm{G})$.

The following theorem relates total strong litact domination number of $G$, diameter of $G$ and domination number of $G$.

Theorem 3.6: For any graph $G$ with more than two vertices, $\boldsymbol{\gamma}_{\mathrm{tsm}}(\mathbf{G})<\operatorname{diam}(\mathbf{G})+\boldsymbol{\gamma}(\mathbf{G})+\mathbf{1}$

Proof: Let $V=\left\{v_{1}, v_{2}, \ldots \ldots, v_{n}\right\}$ be the set of vertices in G. Suppose that there exists two vertices $u$ and $v$ such that the distance, $\operatorname{dist}(\mathrm{u}, \mathrm{v})=\operatorname{diam}(\mathrm{G})$.Let $D=\left\{v_{1}, v_{2}, \ldots \ldots, v_{p}\right\}, 1 \leq p \leq n$ be a minimal dominating set in G such that $|D|=\gamma(G)$. Now we consider $F=\left\{e_{1}, e_{2}, \ldots \ldots, e_{n}\right\} ; F \subseteq E(G)$ and each $e_{i}, 1 \leq i \leq n$ is an element of 


\section{International Advanced Research Journal in Science, Engineering and Technology \\ Impact Factor 7.105 Vol. 9, Issue 1, January 2022 \\ DOI: 10.17148/IARJSET.2022.9140}

$\mathrm{V}(\mathrm{m}(\mathrm{G}))$. That is $e_{i} \in V(m(G))$, as by the definition of litact graph, $V(m(G))=E(G) \cup C(G)$ where $\mathrm{C}(\mathrm{G})$ is the cut vertex set of $G$. Suppose $F_{1}, C_{1}$ are the subsets of $F$ and $C$ respectively such that $D^{\prime}=\left\langle F_{1} \cup C_{1}\right\rangle$ is an strong dominating set which is minimal and it has no isolated vertices in $m(G)$. Clearly $\left|D^{\prime}\right|=\gamma_{\text {tsm }}(G)$. Then we have $\left|D^{\prime}\right| \subset$ $\operatorname{diam}(G)+|D|+1$ and hence $\gamma_{\mathrm{tsm}}(G)<\operatorname{diam}(G)+\gamma(G)+1$.

The ensuing theorem establish the acme for $\gamma_{\mathrm{tsm}}(G)$ in terms of $\gamma(G), \gamma_{c}(G)$

Corollary 3.7: For any graph $G, \gamma_{\mathrm{tsm}}(G) \leq \gamma(G)+\gamma_{\mathbf{c}}(G)+1$.

Proof: Addition of Theorem 3.6 and theorem B we get $\gamma_{t s m}(G) \leq \gamma(G)+\gamma_{c}(G)+1$.

The following Theorem establish the upper bound for $\gamma_{\text {tsm }}(G)$ in terms of $\alpha_{1}(G)$

Theorem 3.7: Every graph $G$, then $\gamma_{\text {tsm }}(G)<2 \alpha_{1}(G)$.

Proof: Suppose $A=\left\{e_{i} / 1 \leq i \leq n\right\}$ be the set of all end edges in $G$. Then $A \cup B$ where $B \subseteq E(G)-A$ has minimum number of edges which covers all vertices of $G$ such that $|A \cup B|=\alpha_{1}(G)$. Let $D \subseteq V(m(G))$ be the minimal dominating of $\mathrm{m}(\mathrm{G})$, if for every vertex $\mathrm{x} \in \mathrm{V}(\mathrm{G})-\mathrm{D}$, there is a vertex $\mathrm{y} \in$ Dwith $\operatorname{deg}(\mathrm{x}) \leq \mathrm{deg}(\mathrm{y})$ and it has no isolated vertices such that $D$ it self forms a $\gamma_{t s m}$ - set.Since $V(m(G))=E(G) \cup C(G)$ where $C(G)$ is the cut vertex set in $G$. But $E(G) \subseteq V(m(G))$ such that $A \subseteq V(m(G))$ which gives contribution to the set $E(G)$ to represent twice to the edge covering number in $G$. Hence $|D| \subset 2|A \cup B|$ which rises to $\gamma_{\text {tsm }}(G)<2 \alpha_{1}(G)$.

The ensuing theorem establish the acme for $\gamma_{\mathrm{tsm}}(G)$ in terms of $\mathrm{p} \& \beta_{1}(G)$.

Corollary 3.8: For any graph $\mathbf{G},\left[\frac{\gamma_{\mathrm{tsm}}(\mathbf{G})}{2}\right]<\mathrm{p}-\boldsymbol{\beta}_{\mathbf{1}}(\mathbf{G})$.

Proof: Substituting Theorem E in Theorem 3.7, we get the result $\left\lfloor\frac{\gamma_{\mathrm{tsm}}(\mathrm{G})}{2}\right\rfloor<\mathrm{p}-\beta_{1}(G)$.

The ensuing theorem interrelates $\gamma(G), \gamma_{t}(G) \& \gamma_{t s m}(G)$

Theorem 3.8: For any graph $G, \gamma_{t s m}(G) \leq \gamma(G)+\gamma_{t}(G)$.

Proof: Let M be a minimal dominating set of G such that $|M|=\gamma(G)$. Let $H \subseteq V(G)-M$ and $H^{\prime} \subseteq H$. Then $\left\langle H^{\prime} \cup M\right\rangle$ has no isolated vertices in G. Suppose $H^{\prime} \cup M$ forms a total dominating set which is minimal in G. Let minimal D be a strong dominating set of $\mathrm{m}(\mathrm{G})$. Assume $K \subseteq V(m(G))-D$ and $K_{1} \subseteq K$ such that $K_{1} \cup D$ forms a minimal total strong dominating set in (G). Then clearly $\left|K_{1} \cup D\right| \leq|M|+\left|H^{\prime} \cup M\right|$ which gives $\gamma_{\text {tsm }}(\mathrm{G}) \leq$ $\gamma(\mathrm{G})+\gamma_{\mathrm{t}}(\mathrm{G})$.

In the following corollary $\gamma_{\mathrm{tsm}}(\mathrm{G})$ is expressed as a sum of $\gamma_{\mathrm{c}}(\mathrm{G})$ and $\gamma_{\mathrm{t}}(\mathrm{G})$.

Corollary 3.9: For any $G, \gamma_{\mathrm{tsm}}(\mathbf{G}) \leq \boldsymbol{\gamma}_{\mathbf{c}}(\mathbf{G})+\boldsymbol{\gamma}_{\mathbf{t}}(\mathbf{G})$

Proof: Addition of theorem 3.8 and theorem $D$ we obtained $\gamma_{t s m}(G) \leq \gamma_{c}(G)+\gamma_{t}(G)$

In the ensuing theorem $\gamma_{\mathrm{tsm}}(\mathrm{G})$ is expressed as a sum of $\alpha_{0}(G)$ and $\operatorname{diam}(G)$.

Theorem 3.9 : For any $\operatorname{graph} G, \gamma_{\mathrm{tsm}}(\mathbf{G}) \leq \boldsymbol{\alpha}_{\mathbf{0}}(\mathbf{G})+\operatorname{diam}(\mathbf{G})$.

Proof: All edges covered by a maximal set of vertices in $\mathrm{T}$ of $\mathrm{G}$ such that $|\mathrm{T}|=\propto_{0}(\mathrm{G})$. Let $V=\left\{v_{1}, v_{2}, \ldots ., v_{n}\right\}$ be the set of vertices in $G$. Suppose that there exists two vertices $u, v \in V(G)$ such that the distance between the two vertices is maximum. That is $\operatorname{dist}(\mathrm{u}, \mathrm{v})=\operatorname{diam}(\mathrm{G})$. Let $C=\left\{v_{1}, v_{2}, \ldots ., v_{i}\right\}, 1 \leq i \leq n$ be a minimal strong dominating set in $\mathrm{m}(\mathrm{G})$. Take $C^{\prime}=V(m(G))-C$ and $C_{1} \subseteq C^{\prime}$ such that deg $(\mathrm{u}, \mathrm{v}) \neq 0$ for $u, v \in V\left(\left\langle C^{\prime} \cup C\right\rangle\right)$ So, $C^{\prime} \cup C$ forms a minimal total strong dominating set in $\mathrm{m}(\mathrm{G})$. Then clearly $\left|C^{\prime} \cup C\right| \subset|T|+\operatorname{diam}(G)$ which implies $\gamma_{\mathrm{tsm}}(G) \leq \alpha_{0}(G)+\operatorname{diam}(G)$.

In the following corollary $\gamma_{\mathrm{tsm}}(G)$ is expressed in terms of $\mathrm{p}, \beta_{0}(G) \& \operatorname{diam}(G)$

Corollary 3.10: For any graph $G, \gamma_{\text {tsm }}(G) \leq p-\beta_{0}(G)+\operatorname{diam}(G)$.

Proof: Substitution of Theorem $E$ in Theorem 3.9 we obtained $\gamma_{\mathrm{tsm}}(G) \leq p-\beta_{0}(G)+\operatorname{diam}(G)$

In ensuing theorem we get a relationship between total strong domination number of $(G)$, edges of $G$ and edge covering of $\mathrm{G}$ 


\section{International Advanced Research Journal in Science, Engineering and Technology \\ Impact Factor 7.105 Vol. 9, Issue 1, January 2022 \\ DOI: $10.17148 /$ IARJSET.2022.9140}

Theorem 3.10: Every graph G, $\left.\mid \frac{\mathrm{q}}{2 \Delta^{\prime}(\mathrm{G})+1}\right\rfloor<\boldsymbol{\gamma}_{\mathrm{tsm}}(\mathrm{G})$

Proof: Let edge set be $E=\left\{e_{i} / 1 \leq \mathrm{i} \leq \mathrm{n}\right\}$ in $\mathrm{G}$ that is $|\mathrm{E}(\mathrm{G})|=\mathrm{q}$ and $\Delta^{\prime}(\mathrm{G})$ be the maximum degree of edge in $\mathrm{G}$. In $\mathrm{m}(\mathrm{G}), \mathrm{D} \subseteq \mathrm{V}(\mathrm{m}(\mathrm{G}))$ be the minimal total strong dominating number then Ditself forms a $\gamma_{\mathrm{tsm}}-$ set.

$$
\begin{aligned}
& \text { Then } 2|\mathrm{D}| \Delta^{\prime}(\mathrm{G})<3 \mathrm{E}(\mathrm{m}(\mathrm{G}))-|\mathrm{D}| \\
& 2|\mathrm{D}| \Delta^{\prime}(\mathrm{G})+|\mathrm{D}|<3|\mathrm{E}(\mathrm{m}(\mathrm{G}))| \ldots \ldots \ldots .
\end{aligned}
$$

By the definition of litact graph since $\mathrm{V}[\mathrm{m}(\mathrm{G})]=\mathrm{E}(\mathrm{G}) \cup \mathrm{C}(\mathrm{G})$

We have $3|\mathrm{E}(\mathrm{m}(\mathrm{G}))|>|\mathrm{E}(\mathrm{G})|$

Also $\left(2 \Delta^{\prime}(\mathrm{G})+1\right)|\mathrm{D}|>|\mathrm{E}(\mathrm{G})|$

We get $3|\mathrm{E}(\mathrm{m}(\mathrm{G}))|>\left(2 \Delta^{\prime}(\mathrm{G})+1\right)|\mathrm{D}|>|\mathrm{E}(\mathrm{G})|=\mathrm{q}$

$$
\begin{aligned}
& \left(2 \Delta^{\prime}(\mathrm{G})+1\right)|\mathrm{D}|>\mathrm{q} \\
& |\mathrm{D}|>\frac{\mathrm{q}}{2 \Delta^{\prime}(\mathrm{G})+1} \\
& \left|\frac{\mathrm{q}}{2 \Delta^{\prime}(\mathrm{G})+1}\right|<\frac{\mathrm{q}}{2 \Delta^{\prime}(\mathrm{G})+1}<\gamma_{\mathrm{tsm}}(\mathrm{G})
\end{aligned}
$$

Hence $\left\lfloor\frac{\mathrm{q}}{2 \Delta^{\prime}(\mathrm{G})+1}\right\rfloor<\gamma_{\mathrm{tsm}}(\mathrm{G})$

In the following theorem we obtain a interrelation between total strong domination number of (G), edge domination number of $\mathrm{G}$ and edge degree of $\mathrm{G}$

Theorem 3. 11: In a graph G, $\left\lfloor\frac{\gamma_{\mathrm{tsm}}(\mathbf{G})}{2}\right\rfloor<\boldsymbol{\gamma}^{\prime}(\mathbf{G})+\Delta^{\prime}(\mathbf{G})$

Proof: Let minimal edge set be $H=\left\{\mathrm{e}_{1}^{\prime}, \mathrm{e}_{2}^{\prime} \ldots \ldots \ldots \mathrm{e}_{\mathrm{n}}^{\prime}\right\}$ in $\mathrm{G}$ such that $\mathrm{N}[\mathrm{H}]=\mathrm{E}(\mathrm{G})$. The edge-dominant set $\mathrm{H} \subseteq \mathrm{E}(\mathrm{G})$ is that each edge in $(\mathrm{E}(\mathrm{G})-\mathrm{H})$ must be adjacent to at least one edge in $\mathrm{H}$. That is $\min |\mathrm{H}|=\gamma^{\prime}(\mathrm{G})$. Let $\mathrm{e}_{\mathrm{i}} \in \mathrm{E}(\mathrm{G})$ be the maximum edge degree in $G$ and edge set be $H=\left\{e_{1}, e_{2} \ldots \ldots e_{n}\right\}$ such that $N\left(H^{\prime}\right) \subset H$ and $\left|H^{\prime}\right|=\Delta^{\prime}(G)$. Thus $|H| \leq$ $\left|\mathrm{E}(\mathrm{G})-\Delta^{\prime}(\mathrm{G})\right|$. Let $\gamma$ - set and minimal $\gamma$ - set in $\mathrm{m}(\mathrm{G})$ be $\mathrm{D}$ and $\mathrm{D}^{\prime}$ respectively whose vertex set is the $\langle\mathrm{V}(\mathrm{m}(\mathrm{G}))-\mathrm{D}\rangle$ which is total strong dominating set where $\mathrm{D}^{\prime} \subseteq \mathrm{D}$. Then $\left|\mathrm{D}^{\prime}\right|=\gamma_{\mathrm{tsm}}(\mathrm{G})$. It follows that $\left\lfloor\frac{\mathrm{D}^{\prime}}{2}\right\rfloor<|\mathrm{H}|+$ $\Delta^{\prime}(\mathrm{G})$.

$\Rightarrow\left\lfloor\frac{\gamma_{\mathrm{tsm}}(\mathrm{G})}{2}\right\rfloor<\gamma^{\prime}(\mathrm{G})+\Delta^{\prime}(\mathrm{G})$.

In the following theorem we expressed a relation among $\gamma_{\mathrm{tsm}}(G), \alpha_{1}(G) \& \beta_{1}(G)$.

Theorem 3. 12: Every graph $\mathbf{G}, \boldsymbol{\gamma}_{\mathrm{tsm}}(\mathbf{G})<2\left(\boldsymbol{\alpha}_{\mathbf{1}}(\mathbf{G})+\boldsymbol{\beta}_{\mathbf{1}}(\mathbf{G})\right)$.

Proof: A set $\mathrm{F} \subseteq \mathrm{E}$ is a set that dominates an edge if each of them in $\mathrm{E}$ is either in $\mathrm{F}$ or is adjacent to an edge in $\mathrm{F}$. That is $\max |F|=\beta_{1}(G)$. Let edge set which covers all the vertices be $F_{1}=\left\{e_{1}, e_{2}, \ldots \ldots e_{n}\right\}$ in $G$. The That is $\min || F_{1} \mid=$ $\alpha_{1}(G)$. Let $D^{\prime}$ be $\gamma_{\text {tsm }}-$ set of G. Clearly $\left|D^{\prime}\right| \subseteq 2\left(\left|F_{1}\right| \cup|F|\right)$. Hence, $\gamma_{\text {tsm }}(G)<2\left(\alpha_{1}(G)+\beta_{1}(G)\right)$.

\section{CONCLUSION}

In the current investigation we attempted to introduce new domination parameters on the litact graph which was introduced by Kulli and Muddebihal [11 \& 4]. We defined new domination variant namely total strong litact domination number on a graph. Further the this work can be extended by defining many new variables like semi cototal strong, semi total strong etc., on the litact graph. As the theory of domination is occupying many areas of Science and Engineering and its applications are getting explored by many researchers who made the area of domination as the thrust area of research, the current work is worth study.

\section{REFERENCES}

1. Cockayne C.J., Dawes R.M and Hedetniemi S.T “Total domination in graphs”, Networks,10, pp:2111-219,1980.

2. F.Harary,(1972) Graph theory, Adison Wesley, Reading mass.

3. H.B.Walikar, B.D.Acharya and E. Sampath Kumar, "Recent developments in the theory of domination in graphs". In MRI lecture notes in Math Mehta Research Institute ., Allahabad,No.1,1979

4. Muddebihal M.H., "Lict and Litact graph of a graph", Journal of analysis and computation, Vol - 3, No - 2, 3343,2006.

5. O.Ore, "Theory of Graphs", American Mathematical Society Colloq.Publications, 38,Providence,1962.

6. Renuka Lakshmi A., Abdul Majeed and Vasundhara Devi J., "Strong litact domination in graphs", Journal of Advanced Research in Dynamical \& Control Systems", Volume 10, Issue 10,2018.

7. Sampathkumar E., and Pushpa Latha L., Strong Weak Domination and Domination Balance in a Graph, Discrete Mathematics, Vol. 161, 235-242,1996. 


\section{International Advanced Research Journal in Science, Engineering and Technology \\ Impact Factor $7.105 \div$ Vol. 9, Issue 1, January 2022 \\ nกI: 10 17148/I $\Delta$ R.ISFT 2n20 0140}

8. T.W.Haynes, S.T. Hedetniemi and P.J. Slater, "Fundamentals of domination in graph", New York, Marcel Dekker, Inc.,1998.

9. T.W.Haynes, S.T. Hedetniemi and P.J. Slater, "Domination in graph", Advanced Topics, New York, Marcel Dekker, Inc., 1998.

10. Vani M., Abdul Majeed and Vasundhara Devi J., "Total litact domination in graphs", Journal of Advanced Research in Dynamical \& Control Systems",Vol. 10, Issue 7,2018.

11. V.R.Kulli, "Theory of Domination in Graphs", Vishwa International Publications, Gulbarga, India, 2010.

12. Alwardi A., Ebadi K., Manrique M. and Soner N., "Semi-strong split domination in graphs", Transactions on Combinatorics, Vol. 3, No. 2, 1-12,2014.

13. Desai, A. R. and Gangadharappa, D. B., "Some Bounds on a Strong Domination Number of a Graph", Journal of Computers \& Mathematical Sciences, Vol.2, No. 3, 525-530,2011.

14.Nicholas T., Sheeba Helen T.,"The Total Strong Split Domination Number of Graphs",International Journal of Mathematics and Statistics Invention Volume 5, Issue 2, 1-3,2017.

15.Rautenbach D.,"Bounds on the strong domination number”, Dis. Math., Vol. 215,2000. 